\title{
Transatlantica
}

Revue d'études américaines. American Studies Journal

François Duban. L'Ecologisme aux Etats-Unis : histoire et aspects contemporains de l'environnementalisme américain.

Paris : L'Harmattan, 2000. 188p.

\section{Alain Suberchicot}

\section{(2) OpenEdition}

\section{Journals}

Édition électronique

URL : http://journals.openedition.org/transatlantica/661

DOI : 10.4000/transatlantica.661

ISSN : 1765-2766

Éditeur

AFEA

Référence électronique

Alain Suberchicot, «François Duban. L'Ecologisme aux Etats-Unis : histoire et aspects contemporains de l'environnementalisme américain. 》, Transatlantica [En ligne], 1 | 2003, mis en ligne le 05 avril 2006, consulté le 29 avril 2021. URL : http://journals.openedition.org/transatlantica/661 ; DOI : https:// doi.org/10.4000/transatlantica.661

Ce document a été généré automatiquement le 29 avril 2021

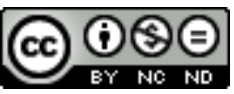

Transatlantica - Revue d'études américaines est mis à disposition selon les termes de la licence Creative Commons Attribution - Pas d'Utilisation Commerciale - Pas de Modification 4.0 International. 


\section{François Duban. L'Ecologisme aux Etats-Unis : histoire et aspects contemporains de l'environnementalisme américain.}

Paris : L'Harmattan, 2000. 188p.

Alain Suberchicot

1 L'ouvrage de François Duban étudie les manifestations actuelles des écologies américaines et en évalue les effets culturels et politiques. Il retrace d'abord les origines de cette prise de conscience de la fragilité des écosystèmes et de la terre américaine. Parmi les précurseurs, on trouve H. D. Thoreau et John Wesley Powell, l'explorateur de l'Ouest. C'est avec John Muir (1838-1914) et Gifford Pinchot (1865-1946) que la réflexion se fait plus spécialisée, et que se fondent les concepts qui sont encore déterminants de nos jours dans la conscience écologique américaine, nous apprend en substance François Duban. Ces deux grandes figures ont permis de marquer les différences, pour ne pas dire les divergences, entre les tenants de la conservation, prônée par Pinchot, favorables à un usage avisé des ressources, et les tenants de la préservation, défendue par John Muir, proposant une protection totale de la nature sauvage. Il y a là un clivage originaire que François Duban a le mérite de mettre en évidence, et dont il suit les conséquences jusque dans les excès de ce que l'on appelle plus près de nous l'écologie profonde.

2 Après avoir analysé les concepts essentiels d'une première phase de développement de l'environnementalisme, François Duban nous oriente très habilement parmi les nombreuses associations écologistes américaines, et il se fait plus politologue qu'historien des idées. On note une connaissance fine des propositions et des débats du Sierra Club, la puissante association californienne de défense de la nature qui voit le jour en 1892, à l'initiative de John Muir, et un examen minutieux de l'action de la Wilderness Society, à partir de sa création en 1935. Ces pages denses mènent à la grande période de l'écologie américaine, en gros de 1970 au début des années 1990, moment où 
l'environnementalisme commence à marquer le pas. C'est là que l'ouvrage de François Duban atteint son point de réflexion critique le plus passionnant. Nous voyons alors se dessiner un paysage paradoxal de l'environnementalisme où les grandes organisations défendent des politiques modérées tandis que les valeurs de l'écologie se diffusent dans le grand public ; nous mesurons l'engouement croissant suscité par l'écologie profonde autour du mouvement Earth First, qui ne craint pas d'opposer la nature aux richesses et aux nécessités de la croissance économique. A lire François Duban, on se pose alors la question suivante: les tenants de la deep ecology (qui ont dû influencer nos Verts hexagonaux, parmi les rangs desquels on ne craint pas de taxer et de représenter en même temps) sont-ils les staliniens de l'Amérique contemporaine ou bien une espèce plus ancienne et typiquement autochtone, des puritains des premiers temps de retour parmi nous pour refuser le monde tel qu'il nous est donné au nom d'un devoir moral? Le livre de François Duban permet aussi de mieux comprendre pourquoi un Al Gore a longuement cultivé son image d'environnementaliste. Il suffit de lire Earth in the Balance (qu'Al Gore a écrit alors qu'il était encore sénateur) pour comprendre, à la lumière des analyses de François Duban, que les valeurs écologistes permettent de se forger une image de radical à peu de frais et de brasser des idées générales. Il sera toujours plus consensuel de se lamenter sur l'effet de serre - puisque c'est un domaine où l'administration Reagan en effet n'a pas été réactive, comme le relève $\mathrm{Al} \mathrm{Gore} \mathrm{-} \mathrm{que}$ de faire des propositions concrètes sur l'avenir de la protection sociale et sur les moyens de combattre la pauvreté urbaine. En outre, nous mesurons, grâce au livre de François Duban, que les valeurs écologistes sont éclectiques, voire clivées. C'est sans doute pour cette raison qu'elles sont aisément récupérées par les hommes politiques, qui y trouvent une réserve d'idées où l'on pourra toujours puiser un discours de substitution faute de pouvoir y trouver une idéologie de rechange. L'environnementalisme n'est donc pas anodin ; il ne l'est pas dans le constat qu'il nous propose ; il ne l'est pas dans sa façon d'être convié au jeu politique.

INDEX

Thèmes : Recensions

\section{AUTEUR}

ALAIN SUBERCHICOT

Université Jean-Moulin - Lyon 3 